\title{
High Suicide Rates Among Unaccompanied Minors/Youth Seeking Asylum in Sweden
}

\author{
Ellenor Mittendorfer-Rutz¹, Ana Hagström², and Anna-Clara Hollander ${ }^{3}$ (i) \\ ${ }^{1}$ Department of Clinical Neuroscience, Karolinska Institutet, Stockholm, Sweden \\ ${ }^{2}$ Centre for Epidemiology and Community Medicine, Stockholm County Council, Stockholm, Sweden \\ ${ }^{3}$ Department of Public Health Sciences, Karolinska Institutet, Stockholm, Sweden
}

\begin{abstract}
Background and aim: We aimed to assess rates and background factors of suicide among unaccompanied minors/youth (10-21 years of age) seeking asylum in Sweden in 2017, and to compare these rates with rates in the Swedish general population of the same age. Method: Data were collected and validated using information from four governmental agencies and two nongovernmental organizations. Suicide rates were calculated for 100,000 individuals. Results: The suicide rate was 51.2 per 100,000 among unaccompanied minors/youth, which compares to 6.1 per 100,000 in the host population. Characteristics of asylum seekers who died by suicide were: male gender (100\%) and from Afghanistan (83\%). Hanging was the predominant method (60\%). Limitations: As estimation of an exact population of asylum seekers is difficult; we overestimated the number of individuals in the population of asylum seekers, resulting in an underestimation of their suicide rates. Conclusion: The suicide rate in unaccompanied minors/youth seeking asylum in 2017 in Sweden can be regarded as very high. Rapid implementation of suicide preventive measures is warranted.
\end{abstract}

Keywords: unaccompanied minors, asylum, suicide, epidemiology

Currently, approximately 65 million individuals are estimated to be forcibly displaced and more than 25 million are refugees (The UN Refugee Agency [UNHCR], 2019). About half of these refugees are minors and a large number migrate without parents or other legal guardians (UNHCR, 2019), so-called unaccompanied refugee minors. In 2015, the unprecedented number of 35,369 unaccompanied minors arrived in Sweden to seek asylum (Migrationsverket, 2018). Those who get their asylum applications approved are granted a Swedish residence permit. Those who are rejected are expected to leave Sweden.

A number of studies show that unaccompanied asylum-seeking minors have a high risk of having experienced trauma and poor mental health (Eide \& Hjern, 2013; Vervliet, Lammertyn, Broekaert, \& Derluyn, 2014). Poor mental health and early traumatic experiences represent major risk factors for suicide (Hawton \& van Heeringen, 2009), but studies on suicide rates in unaccompanied minors seeking asylum in high-income countries are entirely lacking to date.

Asylum seekers cannot be identified in health-related population statistics in Sweden. For this reason, we applied field epidemiological methods in this study. The definition of minors includes generally individuals up to 18 years of age. Still, as some young people, up to 21 years, are cov- ered by social services in Sweden, also unaccompanied young people/youth up to 21 years of age were included in this study and henceforth referred to as unaccompanied minors for brevity.

We aimed to:

1. Assess rates and background factors of suicide among unaccompanied minors (10-21 years) seeking asylum 2017 in Sweden; and

2. Compare these rates with those in the host population of the same age.

\section{Method}

\section{Data Collection}

We gathered data on suicide rates and background factors by contacting 23 different sources, specifically state agencies and nongovernmental organizations (NGOs). Out of these 23 sources, four state agencies and two NGOs provided data. 


\section{Population of Unaccompanied Minors and the Host Population}

It is difficult to estimate the exact population size of asylum seekers as the population size may change on a daily basis. In order to estimate the population size, information was derived from the Migration Agency (MA). To have an estimate covering all possible asylum seekers during 2017, we summed the number of individuals with a new application for asylum during 2017 and the number of individuals with ongoing asylum applications from 2016. The Swedish population size was derived from the official statistics provided by the National Board of Health and Welfare (NBHW).

\section{Information on Number of Suicides}

The number of unaccompanied minors seeking asylum who died by suicide was collected through information from the NGOs ("Vi står inte ut" and "The association of unaccompanied youth") and from reports to the Health and Social Care Inspectorate. Findings from these sources were cross-checked to verify individual information. This information was then validated using the register database on all forensic autopsies held by the National Board of Forensic Medicine (NBFM) in Sweden. Data on the number of suicides in the host population were derived from the NBHW. For both the asylum seekers and the host population, suicides were coded according to the International Classification of Diseases version 10 (ICD-10) codes: X60-X84. Moreover, events of undetermined intent (ICD10 code $\mathrm{Y} 10-\mathrm{Y} 34)$ were included to limit the risk of underreporting as well as variations in case ascertainment. The ICD codes also provided information on the methods of suicide.

\section{Background Factors}

Information on background factors of the asylum seekers was gathered from the MA. Such factors included age, schooling, as well as conditions during premigration and during the asylum process in Sweden.

\section{Data Analysis}

Suicide rates were calculated per 100,000 individuals in the respective population. We performed a sensitivity analysis and calculated suicide rates for unaccompanied minors and the host population between 14 and 18 years of age.
Table 1. Number of suicides, population size and suicide rates per 100,000 individuals for unaccompanied minors seeking asylum (10-21 years of age) and the host population of the same age in Sweden in 2017

\begin{tabular}{lcc}
\hline & Unaccompanied & Host population \\
\hline Suicide $(n)$ & 12 & 82 \\
Population $(n)$ & $23,425^{\star}$ & $1,336,833$ \\
Suicide rate per 100,000 & 51.2 & 6.1 \\
\hline \multicolumn{2}{l}{$\begin{array}{l}\text { Note. *21, 961 ongoing asylum applications from 2016 and 1, 464 new } \\
\text { asylum applications during 2017. }\end{array}$}
\end{tabular}

The study was approved by the Regional Ethical Review Board of Stockholm (dnr 2017/1687-31/2).

\section{Results}

Table 1 shows that the suicide rate for unaccompanied minors was eight times higher than in the host population. The sensitivity analysis for 14-18-year-olds revealed a suicide rate for unaccompanied minors of 40.7 per 100,000 and for the host population of 7.6 per 100,000 .

\section{Background Factors}

All unaccompanied minors who died by suicide in 2017 were young men and most of them from Afghanistan $(83 \%)$. According to the information provided from the MA, many of the asylum-seeking individuals who died by suicide with available information ( $75 \%$ ) had little or no schooling (67\%), had endured harassment and abuse $(56 \%)$, and had experienced violence and poverty before seeking asylum in Sweden (67\%). Suicide by hanging was the most frequent method (about 60\%). All the boys who died by suicide in 2017 had applied for asylum in 2015 .

The boys who died by suicide had different legal status in four broad categories according to the MA:

- Decision pending (ongoing protection claims), $n=5$;

- Rejection, no information on appeal, $n=3$;

- Asylum application approved, $n=2$; and

- Case not opened (no interview), $n=2$.

\section{Discussion}

The suicide rate for unaccompanied minors aged 10-21 years seeking asylum in Sweden was 51.2 per 100,000 in 2017. This is a remarkably high suicide rate both from a national and international perspective (McLoughlin, Gould, \& Malone, 2015). In a study comparing suicide 
rates between countries in 2008 , the highest rate for 15-19-year-olds was 19 per 100,000 in Russia (McLoughlin et al., 2015).

\section{Suicide Methods}

Around $60 \%$ of the unaccompanied minors who died by suicide used hanging as a method. Hanging is a lethal suicide method; about $70 \%$ of people using this method die as a consequence of their suicidal behavior (Gunnell, Bennewith, Hawton, Simkin, \& Kapur, 2005). People who use a method with a high probability of a fatal outcome such as, for example, hanging can therefore be assumed to have a strong suicidal intention, thus a strong intention to die.

The majority of the suicides among unaccompanied minors occurred during an ongoing asylum process without a final decision on their application or their case in court. This finding is in contrast to a common belief that refusal of an application for asylum constitutes a trigger for suicidal behavior. In addition, we found that all unaccompanied minors who died by suicide in 2017 had applied for asylum in 2015. Long processing times in the asylum process might be a cause of mental ill health and therefore a contributing factor to suicidal behavior (Oppedal \& Idsoe, 2015; Socialstyrelsen, 2017). Of note, before 2015 the asylum process was approximately 6 months long, which is a recommended process time for children, and after 2015 the mean process time was over 1 year (Migrationsverket, 2019). The unaccompanied minors who died by suicide in 2017 had several risk factors for suicide, that is, male gender, experience of poverty, traumatic events, and low socioeconomic status (Bridge, Goldstein, \& Brent, 2006; Gomez et al., 2017). Of the unaccompanied minors who died by suicide in 2017, $83 \%$ were from Afghanistan; this can be compared with the share of unaccompanied minors arriving in Sweden in 2015 from Afghanistan being 66\%.

\section{Limitations and Strengths}

To the best of our knowledge, this is the first study internationally to investigate national suicide rates among unaccompanied minors seeking asylum. All suicides among unaccompanied minors were verified by information from registers on coroners' assessments. Moreover, the information on suicide in the host population has been shown to be of good quality (Ludvigsson et al., 2016).

We included all individuals with ongoing and new asylum applications (from 2017) in the calculation of the population size of the unaccompanied minors. This calculation model resulted in an overestimation of the number of unaccompanied minors since, some individuals may have been no longer seeking asylum at the time of their suicide. This, in turn, led to an underestimation of the suicide rate in the target group. It should further be mentioned that an underestimation of the number of suicides may have occurred too. To reduce this risk, we have combined suicides with undetermined causes of death. This practice is frequently applied in both research and reporting of suicide statistics (Mittendorfer-Rutz, Rasmussen, \& Wasserman, 2004; NASP, 2018).

\section{Conclusion}

The suicide rate in unaccompanied minors seeking asylum in 2017 in Sweden can be regarded as very high both from a national and international perspective. Evidence-based suicide prevention methods for adolescents and young adults are available (Mittendorfer-Rutz et al., 2004). Rapid implementation of such suicide preventive measures is warranted in order to prevent the loss of even more young lives. Moreover, continuous monitoring of suicide deaths in this vulnerable population should be established.

\section{References}

Bridge, J. A., Goldstein, T. R., \& Brent, D. A. (2006). Adolescent suicide and suicidal behavior. Journal of Child Psychology and Psychiatry, 47(3-4), 372-394. https://doi.org/10.1111/j.14697610.2006.01615.x

Eide, K., \& Hjern, A. (2013). Unaccompanied refugee children vulnerability and agency. Acta Paediatrica, 102(7), 666-668. https://doi.org/10.1111/apa.12258

Gomez, S. H., Tse, J., Wang, Y., Turner, B., Millner, A. J., Nock, M. K., \& Dunn, E. C. (2017). Are there sensitive periods when child maltreatment substantially elevates suicide risk? Depress Anxiety, 34(8), 734-741. https://doi.org/10.1002/da.22650

Gunnell, D., Bennewith, O., Hawton, K., Simkin, S., \& Kapur, N. (2005). The epidemiology and prevention of suicide by hanging: A systematic review. International Journal of Epidemiology, 34(2), 433-442. https://doi.org/10.1093/ije/dyh398

Hawton, K., \& van Heeringen, K. (2009). Suicide. Lancet, 373(9672), 1372-1381. https://doi.org/10.1016/S0140-6736(09)60372-X

Ludvigsson, J. F., Almqvist, C., Bonamy, A. K., Ljung, R., Michaelsson, K., Neovius, M., ... Ye, W. (2016). Registers of the Swedish total population and their use in medical research. European Journal of Epidemiology, 31(2), 125-136. https://doi.org/10.1007/ s10654-016-0117-y

McLoughlin, A. B., Gould, M. S., \& Malone, K. M. (2015). Global trends in teenage suicide: 2003-2014. QJM, 108(10), 765-780. https://doi.org/10.1093/qjmed/hcv026

Migrationsverket. (2018). Statistics. Retrieved from https://www. migrationsverket.se/English/About-the-Migration-Agency/ Statistics.html

Migrationsverket. (2019). Asyl [Asylum]. Retrieved from https:// www.migrationsverket.se/Om-Migrationsverket/Statistik/Asyl. html 
Mittendorfer-Rutz, E., Rasmussen, F., \& Wasserman, D. (2004). Restricted fetal growth and adverse maternal psychosocial and socioeconomic conditions as risk factors for suicidal behaviour of offspring: A cohort study. Lancet, 364(9440), 1135-1140. https://doi.org/10.1016/S0140-6736(04)17099-2

NASP. (2018). Hur beräknas självmordsstatistik? [How are suicide statistics calculated?] Retrieved from http://ki.se/nasp/hurraknar-man-sjalvmordsstatistik

Oppedal, B., \& Idsoe, T. (2015). The role of social support in the acculturation and mental health of unaccompanied minor asylum seekers. Scandinavian Journal of Psychology, 56(2), 203-211. https://doi.org/10.1111/sjop.12194

Socialstyrelsen. (2017). Analys av situationen i socialtjänsten våren 2017 [Analysis of the situation in the social services in the spring of 2017]. Retrieved from https://www.socialsty relsen.se/globalassets/sharepoint-dokument/artikelkatalog/ ovrigt/2017-6-14.pdf

The UN Refugee Agency (UNHCR). (2019). Figures at a glance. Retrieved from https://www.unhcr.org/figures-at-a-glance.html

Vervliet, M., Lammertyn, J., Broekaert, E., \& Derluyn, I. (2014). Longitudinal follow-up of the mental health of unaccompanied refugee minors. European Child and Adolescent Psychiatry, 23(5), 337-346. https://doi.org/10.1007/s00787-013-0463-1

\section{History}

Received February 1, 2019

Revision received July 30, 2019

Accepted August 9, 2019

Published online December 20, 2019

\section{Conflict of Interest}

We declare no competing interests.

\section{Funding}

This project was funded by the Swedish National Board of Health and Welfare. The funders had no involvement in any aspect of the design of this study, preparation of results, or decision to submit for publication.

\section{ORCID}

Anna-Clara Hollander

(iD https://orcid.org/0000-0002-1246-5804

\section{Anna-Clara Hollander}

Department of Public Health Sciences

Karolinska Institutet

Solnavägen $1 \mathrm{E}$

SE-171 77 Stockholm

Sweden

anna-clara.hollander@ki.se

Ellenor Mittendorfer-Rutz is Professor at Karolinska Institutet in Stockholm, where she is also Acting Head of the Department of Clinical Neuroscience. Dr. Mittendorfer-Rutz's work responds to the complexity of suicidological research by conducting interdisciplinary and translational research, which spans from etiologic and prognostic to prevention and treatment research.

Ana Hagström holds a master's degree in global health. She is specialized in migration-related health issues and evaluation of health programs for refugees/asylum seekers. She has worked in both clinical and academic settings, as well as internationally with displaced persons within the International Federation of Red Cross and Red Crescent Societies.

Anna-Clara Hollander is a licensed clinical psychologist with a $\mathrm{PhD}$ at the Karolinska Institutet using mixed methods to study epidemiological aspects of how the refugee experience and migration affect psychiatric morbidity and mortality and utilization of psychiatric care among both children and adults. 